\title{
Laser Resurfacing after Facial Free Flap Reconstruction
}

\author{
Beom-Jun Kim \\ Yun-Whan Lee \\ $\mathrm{Hi}-\mathrm{Jin}$ You \\ Na-Hyun Hwang \\ Deok-Woo Kim
}

Department of Plastic and Reconstructive Surgery, Korea University Medical Center, Seoul, Korea

Received May 3, 2019

Accepted June 8, 2019

\section{Correspondence \\ Deok-Woo Kim \\ Department of Plastic and Reconstructive Surgery, Korea University Medical Center, 123 Jeokgeum-ro, Danwon-gu, Ansan 15355 , Korea \\ Tel.: +82-31-475-5074 \\ Fax: +82-31-475-5074 \\ E-mail: deokwookimagmail.com}

(C) Korean Society for Laser Medicine and Surgery

(c) This is an open access article distributed under the terms of the Creative Commons Attribution NonCommercial License (http://creativecommons.org/ licenses/by-nc/4.0) which permits unrestricted noncommercial use, distribution, and reproduction in any medium, provided the original work is properly cited.

\section{Background and Objectives}

Skin and soft tissue defects can be treated according to a range of strategies, such as local flap, skin graft, biological dressing, or free flap. On the other hand, free tissue transfer usually leaves a distinct scar with an inconsistency of color or hypertrophy. This problem is highlighted if the defect is located on the face, which could have devastating effects on a patient's psychosocial health.

\section{Materials and Methods}

The authors used an erbium : yttrium-aluminum-garnet (Er:YAG) laser to resurface the free flap skin and match the color with the surrounding facial skin. This study evaluated the effectiveness of laser skin resurfacing on the harmonious color matching of transferred flap.

Patients who had undergone laser resurfacing on facial flap skin between January 2014 and December 2018 were reviewed retrospectively. An ablative 2,940-nm fractional Er:YAG laser treatment was delivered to the entire flap skin at $21 \mathrm{~J} / \mathrm{cm}^{2}$ with the treatment end-point of pinpoint bleeding. Several months later, the clinical photographs were analyzed. The $L^{*} a^{*} b^{*}$ color co-ordinates of both the flap and surrounding normal skin were measured using Adobe Photoshop. The $L^{*} a^{*} b^{*}$ color difference $(\Delta E)$ for the scar and normal surrounding skin were calculated using the following equation: $\Delta E=\sqrt{(\Delta L)^{2}+(\Delta a)^{2}+(\Delta b)^{2}}$

\section{Results}

All five patients were satisfied with the more natural appearance of the flaps. The $\Delta \mathrm{E}$ values decreased significantly from the pre-treatment mean value of 19.64 to the post-treatment mean value of 11.39 (Wilcoxon signed-rank test, $p=0.043$ ).

\section{Conclusion}

Ablative laser resurfacing can improve the aesthetic outcome of free tissue transfer on the face.

\section{Key words}

Lasers; Laser therapy; Ablation techniques; Free tissue flaps 


\section{INTRODUCTION}

Skin and soft tissue defects can occur due to various causes, including trauma and wide excision of malignant lesions. In such cases, surgical techniques such as local flap, skin graft or free flap can be used to cover the defect. ${ }^{1-4}$ Also biologic dressing materials can be used to enhance the healing process of the defect without surgical coverage. Small defects can be dealt with local flap coverage or secondary intention healing, but defects of large size and depth usually require free tissue transfer such as skin graft or free flap coverage. Free tissue transfer usually leaves a distinct scar with inconsistency of color or hypertrophy. This problem is especially highlighted if the defect is located on the face. This prominent mark on the face may make devastating effects on the patient's psychosocial health.

Free flaps are usually required in cases of extensive defect with significant depth, mostly accompanying bone exposure. Various donor sites are used, including radial forearm, anterolateral thigh, scapular, and lateral arm flaps. ${ }^{5-7}$ These distant flaps are valuable tools for defect coverage, but because the donor site skin characteristics are different from the facial skin, the flaps are highly prominent even after significant time has passed postoperatively. Adequate flap debulking techniques could reduce the degree of bulging, but color and texture differences of the flap are difficult to deal with. The authors used erbium : yttrium-aluminum-garnet (Er:YAG) laser to resurface the flap skin in order to match the color with the surrounding facial skin. The purpose of this study was comparative evaluation of color differences, before and after laser treatment.

\section{MATERIALS AND METHODS}

Between January 2014 and December 2018, the medical records of patients who had Er:YAG laser treatment to resurface the facial free flap skin were retrospectively reviewed. Five cases were included in this study. The laser treatments were performed 2.75 months after free flap operation on average. The mean post-laser follow up period ranged from 3.2 to 26.4 months laverage, 8.98 months).

After obtaining written informed consent, the patients' skin was cleansed, and topical anesthetic cream Imixture of $2.5 \%$ lidocaine $\mathrm{HCl}$ and $2.5 \%$ prilocaine, EMLA; Astra Pharmaceuticals, Westborough, MA, USA) was applied for 30 minutes. Ablative 2,940-nm Er:YAG laser treatment was performed on the entire flap skin at $21 \mathrm{~J} / \mathrm{cm}^{2}$ over several passes with the treatment end-point of pinpoint bleeding. Immediately after the treatment, sterile gauze soaked in $0.1 \%$ epinephrine diluted with normal saline was applied on the flap for hemostasis.

Photographic assessments were performed before and several months after treatment. The $L^{*} a^{*} b^{*}$ color co-ordinates of both the flap and the surrounding normal skin were measured by Adobe Photoshop (Adobe Systems Incorporated, San Jose, CA) and Image (National Institutes of Health, Bethesda, Md.). The $L^{*} a^{*} b^{*}$ color difference $(\Delta E)$ for the flap skin and the normal surrounding skin were calculated with the following equation :

$$
\Delta E=\sqrt{(\Delta L)^{2}+(\Delta a)^{2}+(\Delta b)^{2}}
$$

The $L^{*} a^{*} b^{*}$ color differences $(\Delta E)$ were analyzed to verify the treatment outcome. Wilcoxon signed-rank test was performed with SPSS 12.0 software ISPSS Inc., Chicago, IL).

\section{RESULTS}

The average age of the five patients was 53.6 years with a range of 33 to 72 years (Table 1). After the end of treatments, all five patients were satisfied with the more harmonious and natural appearance of the flaps (Fig. 1-5).

The $\Delta \mathrm{E}$ values ranged from 7.09-26.54 and the average value was 19.64 before treatment and 11.99 after treat-

Table 1. Summary of the five cases

\begin{tabular}{|c|c|c|c|c|c|c|}
\hline & Sex/Age & Defect site & Cause & Flap donor site & $\begin{array}{l}\text { Postoperative } \\
\text { time of laser } \\
\text { treatment }\end{array}$ & $\begin{array}{l}\text { Post-laser } \\
\text { follow up }\end{array}$ \\
\hline Case 1. & $M / 65$ & Alar area & Basal cell carcinoma & Chondrocutaneous postauricular flap & 2.4 months & 5.7 months \\
\hline Case 2. & $M / 33$ & Forehead & Traffic accident & Superficial circumflex iliac artery perforator flap & 2.33 months & 4.1 months \\
\hline Case 3. & $\mathrm{M} / 41$ & Forehead & Dermatofibrosarcoma Protuberance & Thoracodorsal artery perforator flap & 2.03 months & 26.4 months \\
\hline Case 4. & $\mathrm{~F} / 57$ & Mastoid area & Chronic otitis media & Anterolateral thigh perforator flap & 4.17 months & 3.2 months \\
\hline Case 5. & $\mathrm{~F} / 72$ & Cheek & Basal cell carcinoma & Superficial circumflex iliac artery perforator flap & 2.83 months & 5.5 months \\
\hline
\end{tabular}



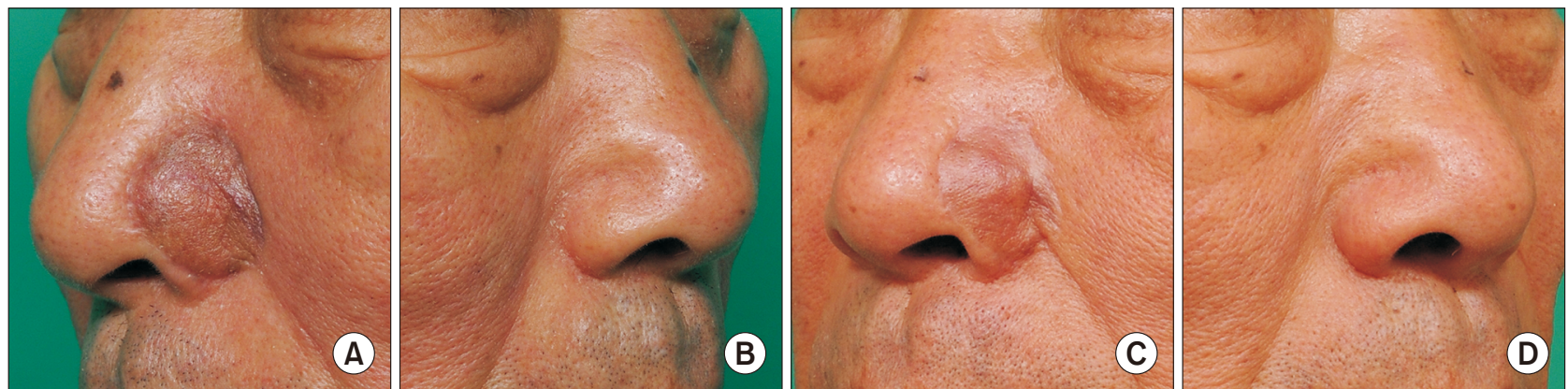

Fig. 1. Clinical photography of Case 1. (A) Pre-treatment flap, (B) pre-treatment contralateral, (C) post-treatment flap, (D) post-treatment contralateral (5.7 months after laser treatment).
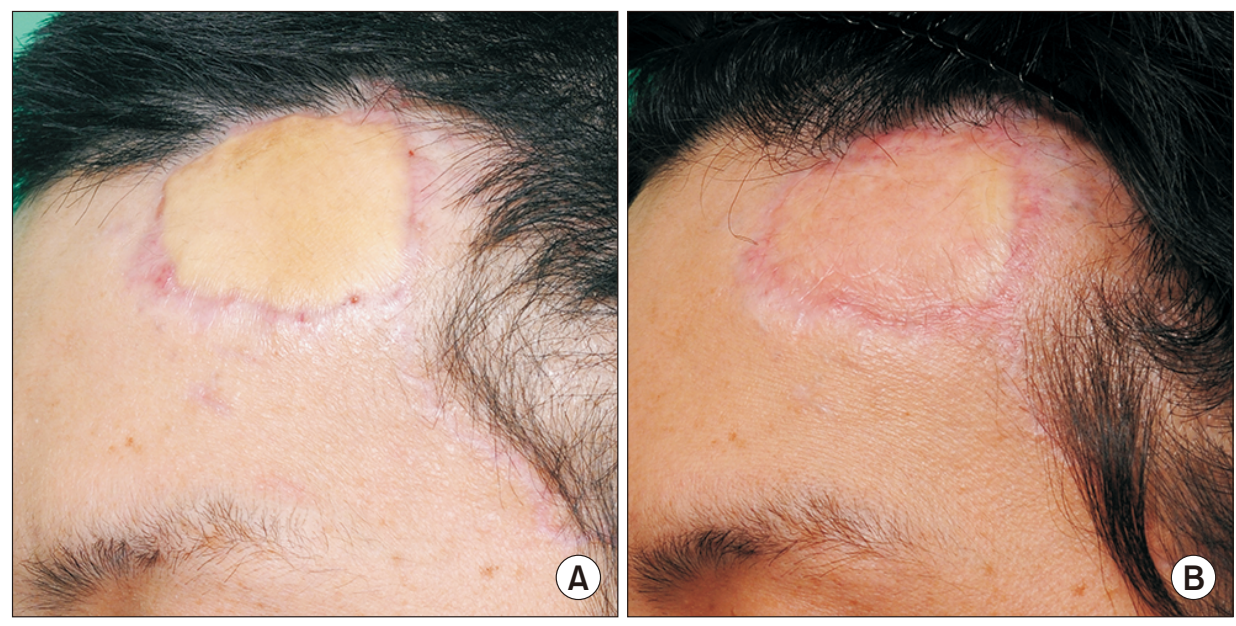

Fig. 2. Clinical photography of Case 2. (A) Pre-treatment, (B) post-treatment (4.1 months after laser treatment).
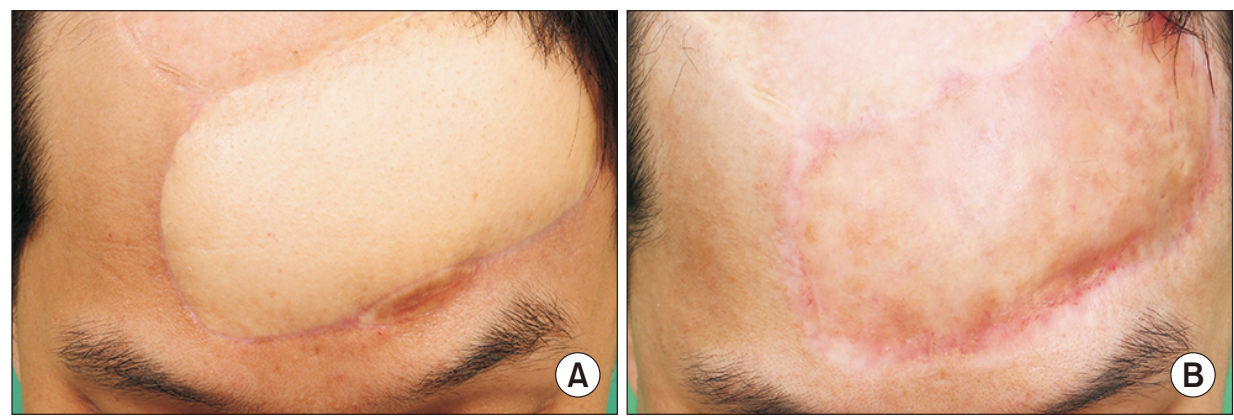

Fig. 3. Clinical photography of Case 3. (A) Pre-treatment, (B) post-treatment (26.4 months after laser treatment).

ment (Table 2). The analysis showed that the $\Delta \mathrm{E}$ values were decreased with statistical significance after laser treatment (Wilcoxon signed-rank test, $p=0.043$ ). The $L^{*}$ and $a^{*}$ component differences before and after ablative laser treatment were also compared. After laser treatment, the $L^{*}$ component values decreased in most of the cases, but the changes did not have statistical significance (Wilcoxon signed-rank test, $p=0.138$ ) (Table 3). After laser treatment, the $a^{*}$ component values increased with statistical significance (Wilcoxon signed-rank test, $p=0.043$ ) (Table 4). Complete skin epithelialization was achieved within 2 weeks and there were no complications in all five cases.

\section{DISCUSSION}

Deep and large defects caused by trauma of cancer usually require free tissue transfer. Although it is a valuable procedure for the reconstruction, patient satisfaction is hard to achieve. Free flaps from distant donor sites have different texture and color, making the flap highly prominent and unnatural. This problem is magnified if the 


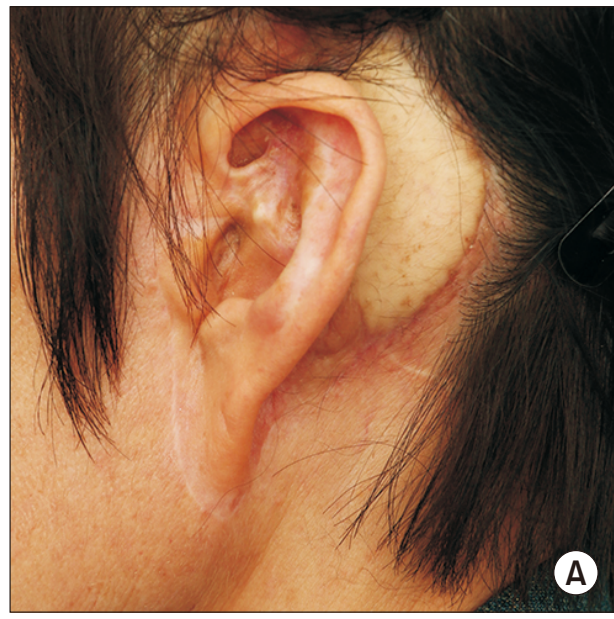

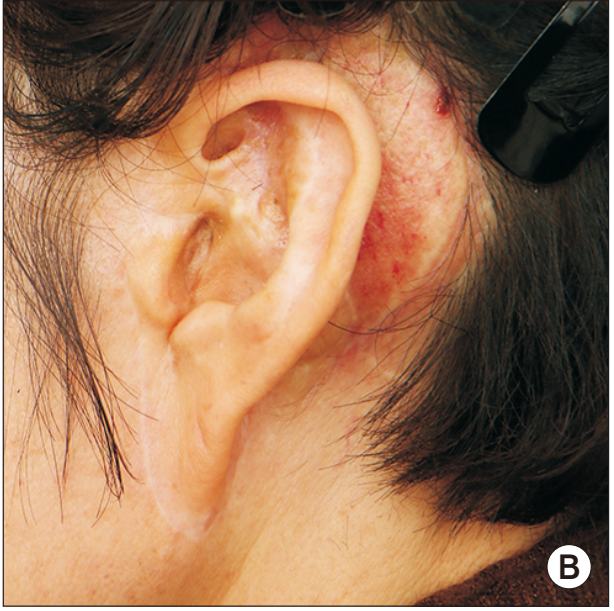

Fig. 4. Clinical photography of Case 4. (A) Pre-treatment, (B) post-treatment (3.2 months after laser treatment).
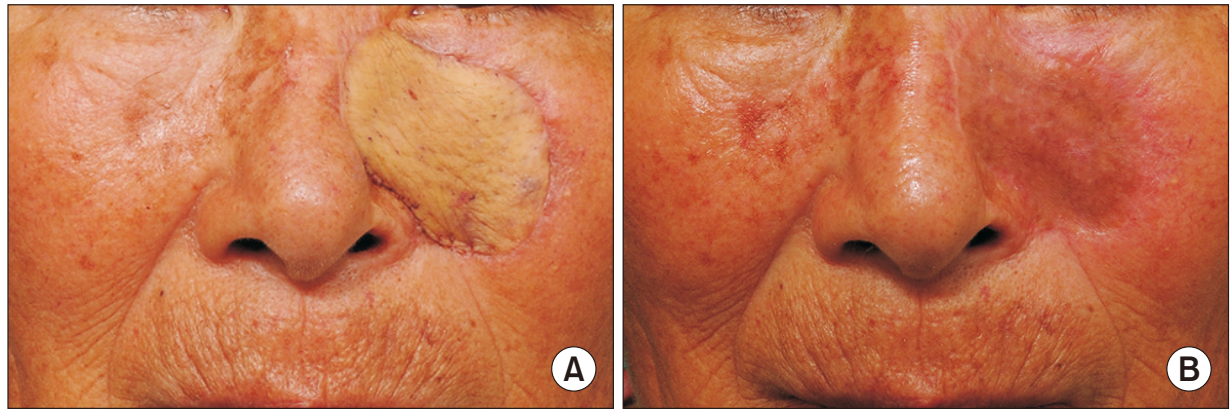

Fig. 5. Clinical photography of Case 5. (A) Pre-treatment, (B) post-treatment (5.5 months after laser treatment).

Table 2. The $L^{*} a^{*} b^{*}$ color differences $(\Delta \mathrm{E})$ before and after ablative laser treatment

\begin{tabular}{lccc}
\hline & Pre treatment $\Delta \mathrm{E}$ & Post treatment $\Delta \mathrm{E}$ & Change of $\Delta \mathrm{E}$ \\
\hline Case 1. & 24.43 & 21.03 & -3.40 \\
Case 2. & 7.70 & 4.22 & -3.48 \\
Case 3. & 26.54 & 13.00 & -13.54 \\
Case 4. & 22.87 & 11.59 & -11.28 \\
Case 5. & 16.68 & 7.09 & -9.59 \\
\hline
\end{tabular}

The analysis indicated that the $\Delta \mathrm{E}$ values were improved with statistical significance after laser treatment (Wilcoxon signed-rank test, $p=0.043$ ).

Table 3. The $L^{*}$ component differences before and after ablative laser treatment

\begin{tabular}{lccc}
\hline & Pre treatment $L^{*}$ & Post treatment $L^{*}$ & Change of $L^{*}$ \\
\hline Case 1. & 150.22 & 165.35 & +15.133 \\
Case 2. & 215.45 & 195.94 & -19.512 \\
Case 3. & 217.14 & 196.05 & -21.085 \\
Case 4. & 207.45 & 196.17 & -11.287 \\
Case 5. & 187.83 & 157.33 & -30.499 \\
\hline
\end{tabular}

The $L^{*}$ values decreased in most of the cases, but the changes did not have statistical significance (Wilcoxon signed-rank test, $p=$ $0.138)$.
Table 4. The $a^{*}$ component before and after ablative laser treatment

\begin{tabular}{cccc}
\hline & Pre treatment $a^{*}$ & Post treatment $a^{*}$ & Change of $a^{*}$ \\
\hline Case 1. & 178.01 & 183.059 & +5.049 \\
Case 2. & 172.585 & 179.234 & +6.649 \\
Case 3. & 173.828 & 177.66 & +3.832 \\
Case 4. & 169.151 & 177.978 & +8.827 \\
Case 5. & 175.349 & 183.762 & +8.413 \\
\hline
\end{tabular}

The analysis indicated that the $a^{*}$ values were increased with statistical significance after laser treatment (Wilcoxon signed-rank test, $p=0.043$ ).

defect is located on the face, forcing the patients to hide their faces with hats and masks. Egeler et al. assessed long term patient reported outcomes with health survey (36-Item Short-Form) following free flap coverage on lower extremities. Patients reported poor mental component scores and social functioning. ${ }^{8}$

Ablative laser therapy with Er:YAG or CO2 lasers are used widespread for various indications. The $\mathrm{CO} 2$ laser has 10,600 nm wavelength, which allows strong absorption of the emitted light by tissue water. This rapidly vaporizes the targeted tissue with immediate contraction of the ablated areas. Er:YAG lasers emit 2,940 nm 
wavelength in the infrared range. This frequency is closer to the peak absorption wavelength of water, resulting 16 times greater absorption coefficient than the $\mathrm{CO} 2$ laser. These lasers allow effective skin resurfacing for various skin lesions without thermal injury. ${ }^{10-12}$

Burm et al. introduced laser hole technique using nonfractional carbon dioxide laser to treat hypopigmented scars. Hypopigmented scars usually have glossy surface with minimal skin pores. They made multiple random holes, 1 to $3 \mathrm{~mm}$ apart from each other, to mimic the natural skin pores surrounding the scar. They achieved both color and texture improvement with high satisfaction from patients. ${ }^{13}$ This technique may be highly effective for small scars with mild color differences, but may not have the same effect on large flap surfaces with already existing skin pores of the donor site.

In our clinical experience, Er:YAG laser resurfacing on the flap skin resulted in improvement of color similar to the surrounding normal skin. Because color is a subjective factor, they were quantified by $L^{*} a^{*} b^{*}$ color differences $(\Delta E)$ obtained from the digital photographs. Using Adobe Photoshop (Adobe Systems Incorporated, San Jose, CA), a square sample of the flap skin and the corresponding contralateral normal skin were each obtained. If the contralateral skin is not adequate for comparison due to hair or skin lesion, a sample from normal skin just adjacent to the flap was used. The samples were each separated in to 3 components $\left(L^{*}, a^{*}, b^{*}\right)$ using Adobe Photoshop. The $L^{*}$ component shows the brightness of the sample, representing the amount of pigmentation of the skin. The $a^{*}$ and $b^{*}$ components represent the color coordinate. To be specific, the $a^{*}$ component is correlated with redness, which could represent the vascularity of skin. The mean values of the square samples separated into each components were measured using ImageJ (National Institutes of Health, Bethesda, Md.) (Fig. 6). The $L^{*} a^{*} b^{*}$ color difference $(\triangle E)$ was obtained by calculating the distance between color coordinates of the flap and normal skin as the equation previously mentioned. The

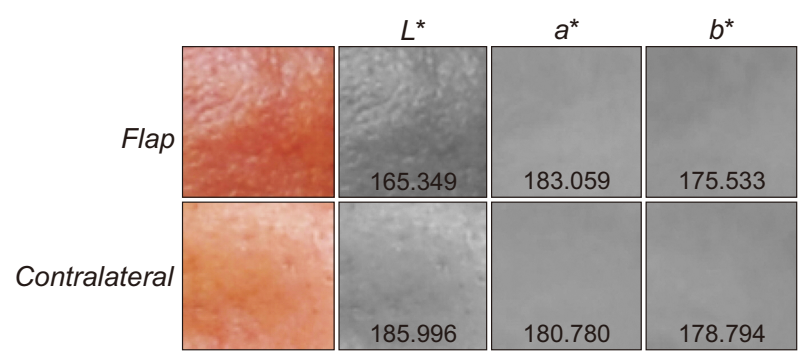

Fig. 6. The $L^{*} a^{*} b^{*}$ color co-ordinates of Case 1. Post-treatment photography.
$L^{*} a^{*} b^{*}$ color differences $(\Delta E)$ of the pretreatment photo and the post-treatment photo were each obtained and compared. ${ }^{14}$ Statistical analysis revealed significant difference between the pretreatment and post-treatment groups, showing consistency with the visual improvement and patient satisfaction.

The mechanism of the improvement in color after laser ablation is not fully clarified. The authors suggest that in the phase of wound healing after the ablation of the flap skin, some cells from the surrounding normal skin may migrate on to the damaged flap skin, reducing the color differences. Aragona et al. defined stem cell dynamics in wound healing process of mouse skin. With immunostaining, they demonstrated the rolls of surrounding tissue of the wounded area, which led to cell migration and wound healing of the defect. ${ }^{15,16}$ Also increase of skin vascularity led to pink skin color, which reduced the $L^{*}$ component and increased the $a^{*}$ component. Although skin texture was not quantitatively assessed, it also improved after laser treatment. This study was limited because of its retrospective design and the small number of cases analyzed. The study was performed only on flaps located on the face. Further study is required to apply the same treatment on flaps located on different locations.

\section{CONCLUSION}

Ablative laser resurfacing can improve aesthetic outcome of free tissue transfer on face. It should be considered as a treatment option for color mismatch of the prominent free flaps.

\section{CONFLICTS OF INTEREST}

We have no potential conflicts of interest relevant to this article to report.

This article has been completed without any financial support.

\section{REFERENCES}

1. Bertrand B, Honeyman CS, Emparanza A, McGurk M, Ousmane Hamady IE, Schmidt A, et al. Twenty-five years of experience with the submental flap in facial reconstruction: evolution and technical refinements following 311 cases in Europe and Africa. Plast Reconstr Surg 2019;143:1747-58.

2. Wang S, Zhang Z, Xu Z, Duan W. Reconstruction of a subtotal upper lip defect with a facial artery musculomucosal flap, kite flap, and radial forearm free flap: a case report. World J Surg Oncol 2018;16:194. 
3. Kant SB, Ferdinandus PI, den Kerckhove EV, Colla C, der Hulst RRWJV, Piatkowski de Grzymala AA, et al. A new treatment for reliable functional and esthetic outcome after local facial flap reconstruction: a transparent polycarbonate facial mask with silicone sheeting. Eur J Plast Surg 2017;40:407-16.

4. Heller L, Cole P, Kaufman Y. Cheek reconstruction: current concepts in managing facial soft tissue loss. Semin Plast Surg 2008;22:294-305.

5. Sarukawa S, Kamochi H, Noguchi T, Sunaga A, Uda H, Mori $Y$, et al. Free-flap surgical correction of facial deformity after anteromedial maxillectomy. J Craniomaxillofac Surg 2017:45:1573-7.

6. Zhou W, He M, Liao Y, Yao Z. Reconstructing a complex central facial defect with a multiple-folding radial forearm flap. J Oral Maxillofac Surg 2014;72:836.e1-4.

7. Aldelaimi TN, Khalil AA. Reconstruction of facial defect using deltopectoral flap. J Craniofac Surg 2015;26:e786-8.

8. Egeler SA, de Jong T, Luijsterburg AJM, Mureau MAM. Longterm patient-reported outcomes following free flap lower extremity reconstruction for traumatic injuries. Plast Reconstr Surg 2018;141:773-83.

9. Preissig J, Hamilton K, Markus R. Current laser resurfacing technologies: a review that delves beneath the surface. Semin
Plast Surg 2012;26:109-16.

10. You HJ, Kim DW, Yoon ES, Park SH. Comparison of four different lasers for acne scars: resurfacing and fractional lasers. J Plast Reconstr Aesthet Surg 2016;69:e87-95.

11. Kang DH, Park SH, Koo SH. Laser resurfacing of smallpox scars. Plast Reconstr Surg 2005;116:259-65; discussion 266-7.

12. Park SH, Koo SH, Choi EO. Combined laser therapy for difficult dermal pigmentation: resurfacing and selective photothermolysis. Ann Plast Surg 2001;47:31-6.

13. Burm JS, Lee YK, Cho JY. Treatment of facial hypopigmented scars by the laser hole technique using a nonfractional carbon dioxide laser in Asians. Plast Reconstr Surg 2018;142:126e32e.

14. Kim DW, Hwang NH, Yoon ES, Dhong ES, Park SH. Outcomes of ablative fractional laser scar treatment. J Plast Surg Hand Surg 2015;49:88-94.

15. Aragona M, Dekoninck S, Rulands S, Lenglez S, Mascré G, Simons BD, et al. Defining stem cell dynamics and migration during wound healing in mouse skin epidermis. Nat Commun 2017;8:14684.

16. Park SH, Yeo WC, Ko WS, Noh NK, Park JW, Yoon CS. Laser dermatology plastic surgery. 2nd ed. Seoul, Korea: Koonja; 2014. p.310-65. 